\title{
Imipenem and normal saline with cyclophosphamide have positive effects on the intestinal barrier in rats with sepsis
}

\author{
Junting Yang ä, Shunwen Zhang ${ }^{\mathrm{b} \#}$, Jiangdong Wua , Jie Zhangc, Jiangtao Dongc, Peng Guoc, Suyu Tangc, \\ Wanjiang Zhang ${ }^{\mathrm{a}}$, Fang $\mathrm{Wu}^{\mathrm{a}}$
}

\begin{abstract}
Background. Sepsis is a life-threatening organ dysfunction caused the dysregulation of host inflammatory response and immunosuppression to infection Early recognition and intervention are hence of paramount importance. In this respect the "sepsis bundle" was proposed in 2004 to be instituted in cases of suspected sepsis.

Objective and Hypothesis. We hypothesised that a combination treatment of the sepsis bundle with cyclophosphamide would improve the function of the intestinal mucosa and enhance survival in rats with induced sepsis.

Methods and Results. Sprague-Dawley rats were divided into 5 different groups: sham, cecal ligation and puncture (CLP), cyclophosphamide (CTX), imipenem+normal saline (NS) and imipenem+NS+CTX. Cecal ligation and puncture were used for inducing the polymicrobial sepsis. Western-blot was used to measure the occludin protein, and ELISA for examining the plasma level of cytokines IL-6, IL-10 and TNF-a. TUNEL assay for testing the intestinal mucosal apoptosis, and hematoxylin-eosin staining for observing the intestinal mucosal changes. The permeability of intestinal mucosa was determined by the plasma level of FD-70. The results showed that the combination treatment of the sepsis bundle with cyclophosphamide attenuated cytokine levels, inhibited epithelial cell apoptosis and improved the function of the intestinal barrier. The survival rate of the group treated with the combined therapy was significantly higher than that of the other groups.

Conclusion. The combination treatment of sepsis bundle with cyclophosphamide improves the function of the intestinal barrier and enhances survival in septic rats.
\end{abstract}

Key words: sepsis, sepsis bundle, cyclophosphamide, intestinal barrier

Received: November 27, 2017; Accepted: June 1, 2018; Available online: June 12, 2018

https://doi.org/10.5507/bp.2018.032

\author{
${ }^{a}$ Department of Pathophysiology, Shihezi University School of Medicine, North 3 Road, Shihezi, Xinjiang, 832002, China \\ ${ }^{6}$ The First School of Clinical Medicine, Nanjing Medical University, Nanjing, Jiangsu Province, 211166, China \\ 'The First Affiliated Hospital, Shihezi University School of Medicine, North 3 Road, Shihezi, Xinjiang, 832002, China \\ "These authors contributed equally to the work \\ Corresponding authors: Wanjiang Zhang, e-mail:zwj1117@126.com and Fang Wu, e-mail:xjwufang@126.com
}

\section{INTRODUCTION}

Sepsis is a life-threatening organ dysfunction caused by the dysregulated host response to infection ${ }^{1,2}$. Sepsis and septic shock are major healthcare problems, affecting millions of people globally and killing more than one in four patients $\mathrm{s}^{3,4}$. Further, the incidence is increasing ${ }^{5}$. The sepsis bundle was proposed by medical experts in 2004, and included in the goal direct therapy of (mainly fluid resuscitation), antibiotics, glucocorticoids, respiratory support and others used in the care of patients with severe sepsis ${ }^{6}$. Previous studies showed the disorder of the bacteria count in the body was due to the abuse of antibiotics and revealed that the most sensitive and healthy bacteria are inhibited or destroyed, leading to the survival advantage of drug-resistant bacteria, proliferation, double and overlapping infection ${ }^{7,8}$. The mechanism of sepsis is thought to be an inflammation balance disorder, leading to immune dysfunction. Proinflammatory cytokines such as tumor necrosis factor (TNF- $\alpha$ ) and IL-6 are closely related to the occurrence and development of inflammation. The TNF- $\alpha$ is one of the main inflammation factors in promoting inflammatory cytokines in the early period of sepsis, and plays an important role in the immune defense reaction that is the key reason for endotoxin damage ${ }^{9}$. Inflammation plays a significant role in the mortality of polymicrobial sepsis, and low doses of immunosuppressants can enhance the survival of mouse model of sepsis ${ }^{10}$. We hypothesised that a combination treatment of the sepsis bundle with cyclophosphamide would improve the function of the intestinal mucosa and enhance survival. We used the cecal ligation and puncture (CLP) model, which causes polymicrobial infection from leakage of stool from the cecal puncture and ischemic tissue damage from ligating the cecal segment of the large intestine ${ }^{11}$. Quantitative and qualitative analysis of the CLP rat model were used to test our hypothesis.

\section{MATERIALS AND METHODS}

\section{Animals}

Male Sprague-Dawley (SD) rats (8-10 weeks old, body weights of $200-300 \mathrm{~g}$ ) from the Animal Center of Xinjiang Medical University (Xinjiang, China) were used in the experiments, and the study protocol was approved 
by the ethics committee of the Medical College of Shihezi University.

\section{Experimental design and sample sizes}

The SD rats were randomly divided into 5 groups. A: the sham group; B: the cecal ligation and puncture (CLP) group; C: the CLP + cyclophosphamide (CTX) group; D: the CLP + imipenem + normal saline (NS) group and E: the CLP +imipenem + NS +CTX group. The sham group only received a sham operation without CLP. A minimum of 6 rats per group was used to detect the pathological changes, cytokines levels, apoptosis index of intestinal mucosal cells, and the occludin protein level. All rats were first euthanized at $24 \mathrm{~h}$ after the CLP procedure through intraperitoneal injection of $10 \%$ chloral hydrate $(0.35$ $\mathrm{mL} / 100 \mathrm{~g}$ ). There were no signs of stress in the animals.

\section{GENERATION OF SEPSIS MODEL}

The rats were starved for $12 \mathrm{~h}$ before experimentation with free access to water. For the intraperitoneal injection (i.p) of $10 \%$ chloral hydrate $(0.35 \mathrm{~mL} / 100 \mathrm{~g})$, a small midline abdominal incision was made. The cecum was ligated distal to the ileocecal valve without causing any intestinal obstruction, punctured twice with an 18-gauge needle and then gently squeezed to extrude a small amount of stool. The cecum was placed into the abdomen, and then closed in layers ${ }^{11,12}$. To obtain comparable effects to septic patients in hospital receiving relevant therapy, $2 \mathrm{~h}$ after CLP, all rats in the CLP+cyclophosphamide (CTX) group received $10 \mathrm{mg} / \mathrm{kg}$ of cyclophosphamideand i.p. injection; the rats in the CLP+imipenem+ normal saline (NS) group received $120 \mathrm{mg} / \mathrm{kg}$ of imipenem, $35 \mathrm{~mL} / \mathrm{kg}$ of normal saline and the i.p. (imipenem $+\mathrm{NS}$ ), and the rats in the CLP+imipenem+NS+CTX group received $120 \mathrm{mg} / \mathrm{kg}$ of imipenem, $10 \mathrm{mg} / \mathrm{kg}$ of cyclophosphamide, $35 \mathrm{~mL} / \mathrm{kg}$ of normal saline (imipenem+NS+CTX) and i,p. injection $^{1,6,13-17}$. The rats that were sacrificed $24 \mathrm{~h}$ after CLP.

\section{Survival analysis}

A minimum of 10 rats per group was used for measuring survival rate. After the treatment, the animals were given free access to food and water and observed for 7 days. The survival rates were recorded daily.

\section{Detection of Plasma cytokines}

Blood samples were taken from the aorta and abdominalis, centrifuged $\left(12000 \mathrm{r} / \mathrm{min}, 4{ }^{\circ} \mathrm{C}\right)$ and stored at -80 ${ }^{\circ} \mathrm{C}$ until use. The concentrations of TNF- $\alpha$, IL- 6 and IL10 were determined by Enzyme Linked Immunosorbent Assay (ELISA) kits (Shanghai Westang, China).

\section{Histopathological examination}

The intestinal tissues were harvested at $24 \mathrm{~h}$ after CLP and fixed in 4\% paraformaldehyde. They were then embedded in paraffin, sectioned and stained with the hematoxylin and eosin (HE) reagent. The images were observed for any mucosal injury using a light microscope ( $\times 100$ magnification $)$.

\section{Apoptosis index of intestinal mucosal cells}

The apoptosis index was assessed by the TUNEL method using a TUNEL staining kit (Roch) according to the manufacturer's instructions. The intestinal mucosal cells in the stained tissues in five different random visual fields were counted as five replicates.

\section{Western blot}

The intestinal tissues were snap frozen and stored at $-80{ }^{\circ} \mathrm{C}$ until use. Tissues were ground with an automatic homogenizer in chilled SDS-lysis buffer and then centrifuged. The protein concentration in the supernatant was measured using a BCA protein assay kit (Thermo, USA) and an aliquot of $40 \mu \mathrm{g}$ protein per sample was used for SDS-PAGE and Western blot. Intensities of immunereactive bands were quantified using ImageJ $(1.51 \mathrm{~K}$, USA). The occludin/ $\beta$-actin protein ratio was calculated for comparison between samples. The primary antibody was rabbit monoclonal [EPR8208] to occludin (Abcam, UK) and the secondary antibody, Goat Anti-Rabbit IgG H\&L (Abcam, UK) were used to examine the occlucin protein in each sample.

\section{Intestinal permeability}

A minimum of 6 rats per group were used for measuring intestinal permeability. The rats from each group were gavaged after $24 \mathrm{~h}$ of drug intervention with $0.5 \mathrm{~mL}$ of fluorescein isothiocyanate-dextran (FD-70, $25 \mathrm{mg} / \mathrm{mL}$, molecular mass $70 \mathrm{kD}$, Sigma) and $5 \mathrm{~h}$ before sacrifice ${ }^{18}$. The measurement of intestinal permeability was carried out as described previously ${ }^{19}$. Briefly, at the time of sacrifice, blood was collected from the portal vein and centrifuged at $10,000 \mathrm{rpm}$ and $4{ }^{\circ} \mathrm{C}$ for $10 \mathrm{~min}$. Plasma $(50 \mu \mathrm{L})$ was then diluted with an equal amount of sterile phosphate-buffered saline ( $\mathrm{pH}$ 7.4). The concentration of FD-70 was measured using a fluorospectrometer (BioTek, Winooski, VT) at an excitation wavelength of $490 \mathrm{~nm}$ and an emission wavelength of $520 \mathrm{~nm}$ and quantified against serially diluted standards. All samples and standards were run in duplicate.

\section{Statistical analysis}

The results are expressed as means \pm SD. All statistics analyses were carried out with Prism 5.0 (GraphPad software, USA) and SPSS 20.0 (SPSS Inc., Chicago, IL, USA). Differences between groups were assessed using one-way analysis of variance (ANOVA), followed by LSD-t test. Mortality was analyzed using Kaplan-Meier survival curves, and then log-rank test for statistical differences in survival rates. We set a $P$-value of $<0.05$ as statistically significant.

\section{RESULTS}

Effect of combined treatment of imipenem, normal saline and cyclophosphamide on survival time in rats

Figure 1 shows the survival curves and median survival time of the rats after relevant treatments. The survival curves show statistically significant differences among all groups. The median survival time in sham, CLP, CTX, imipenem+NS and imipenem+NS+CTX group was $7 d$, 


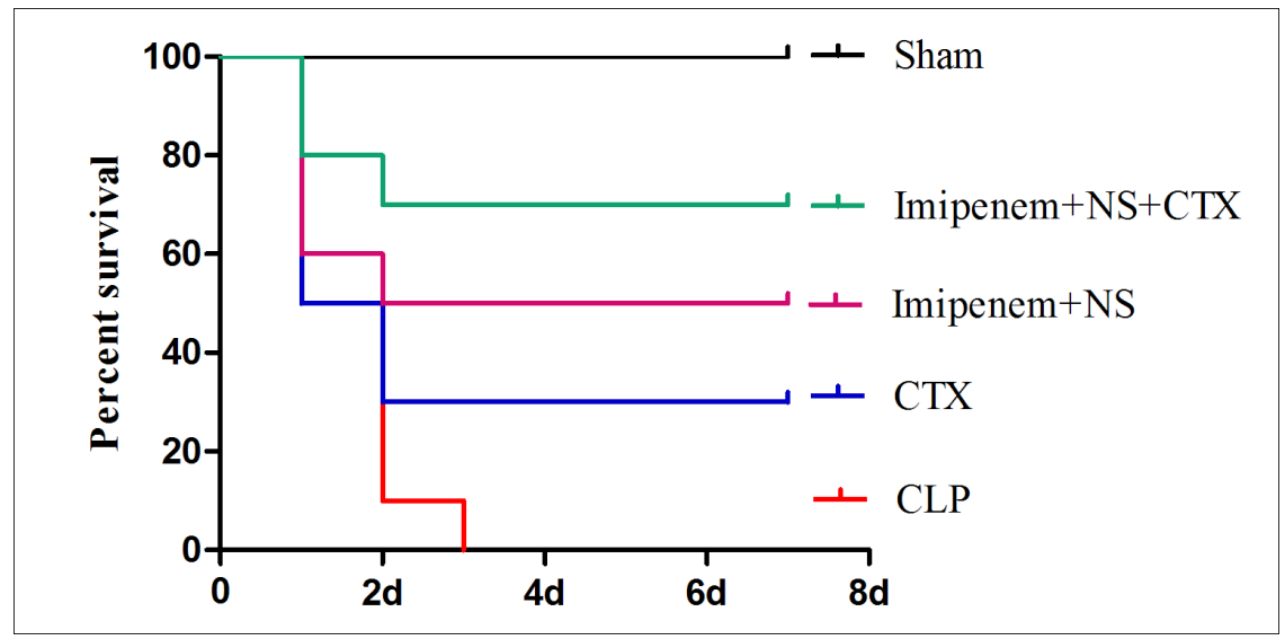

Fig. 1. The survival curve of septic rats (log-rank test $P<0.05$ ).

The survival values are expressed as mean $\pm \mathrm{SD}$, and the significant statistical threshold is $P<0.05$.

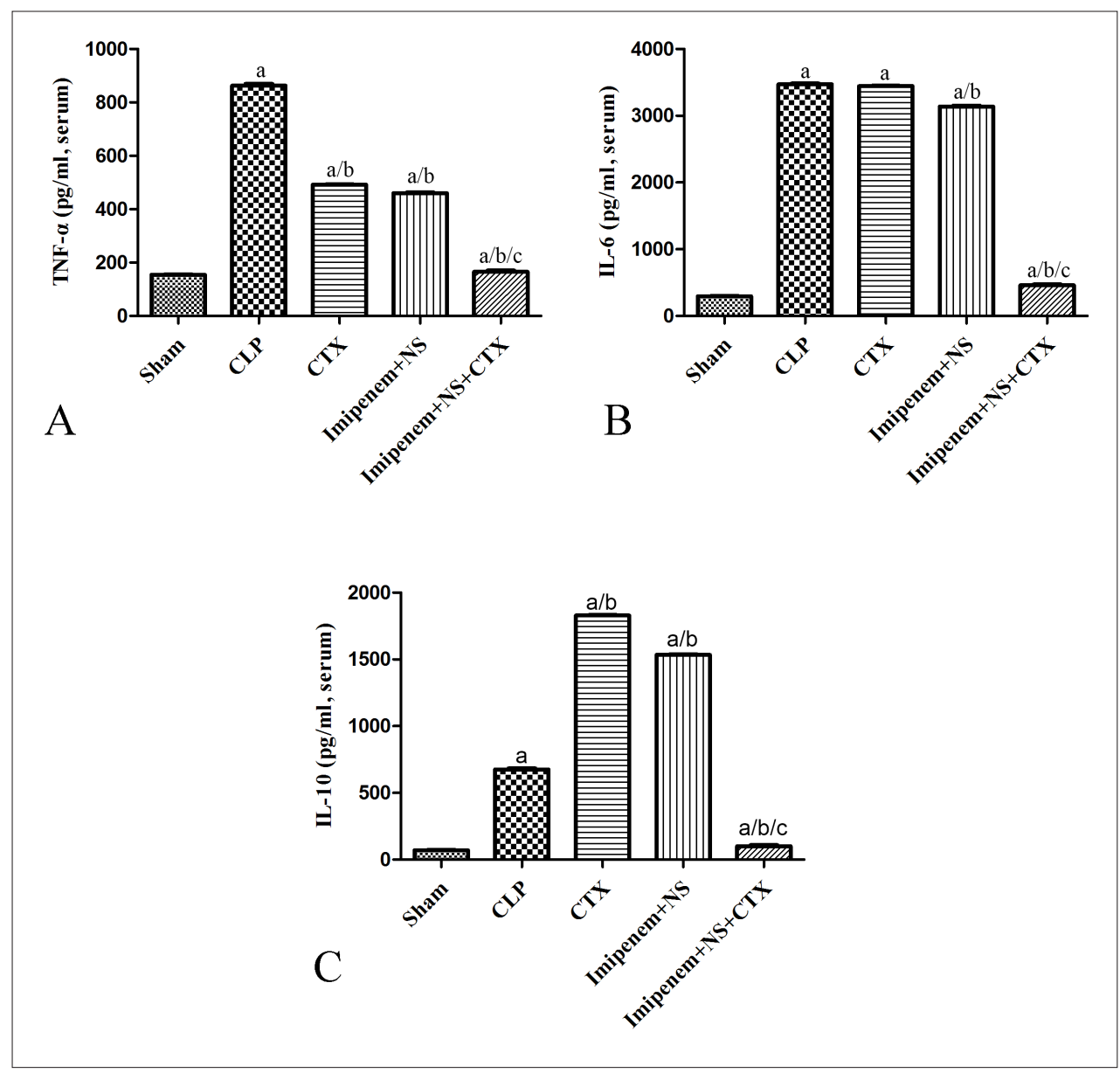

Fig. 2. Measurement of the serum levels of cytokines TNF- $\alpha$ (A), IL-6 (B) and IL-10 (C). The levels are expressed as mean \pm SD with significant threshold $P<0.05$. Compared to the sham group, there was statistically significant difference $(P<0.05)$; Compared to the CLP group, there was statistically significant difference $(P<0.05)$; Compared the imipenem $+\mathrm{NS}$ group with the imipenem+NS+CTX group, there was statistically significant difference $(P<0.05)$ 

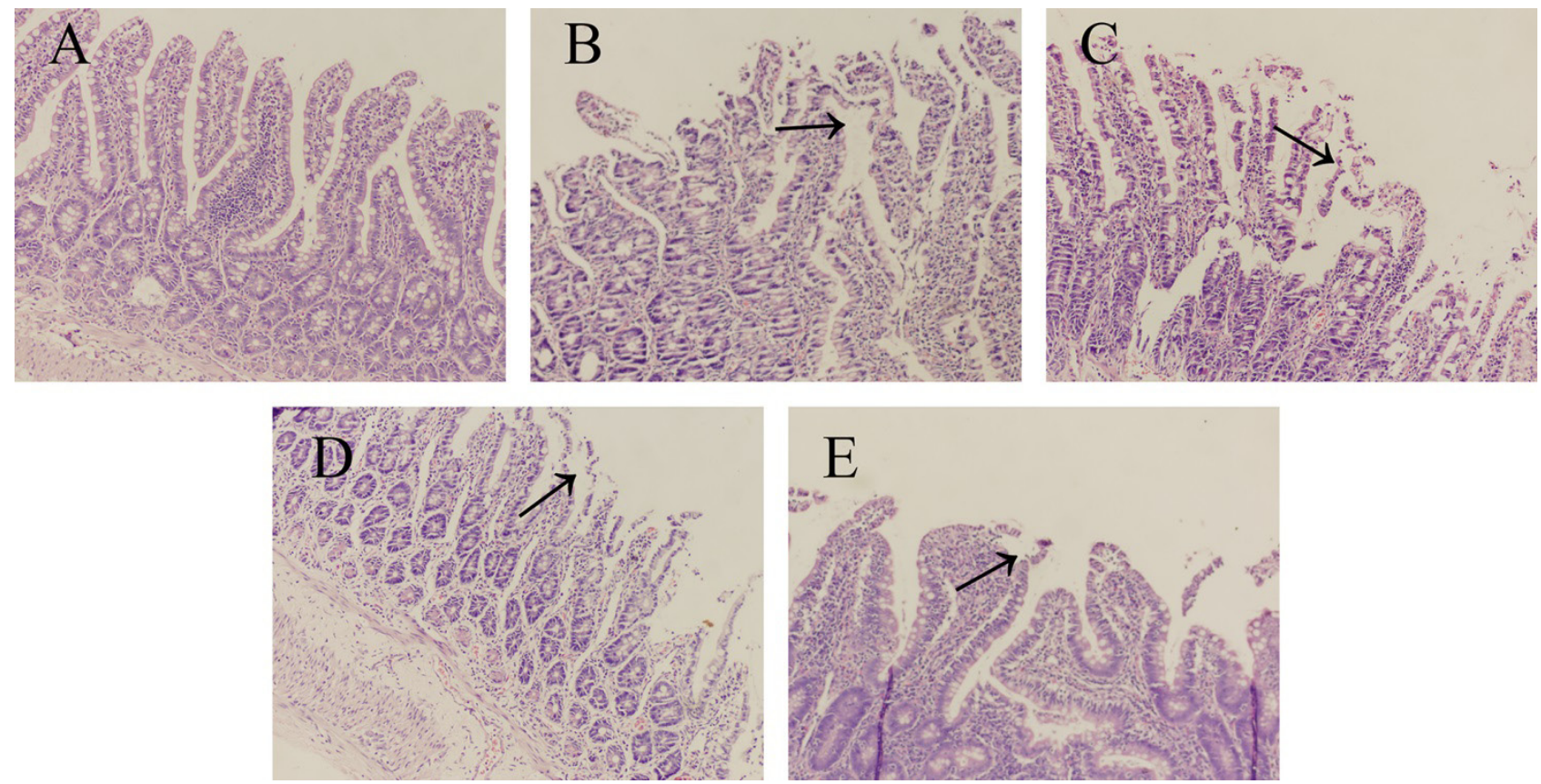

Fig. 3. The pathological sections of intestinal tissue and hematoxylin-eosin staining.

The arrows indicate the damage of the cells.
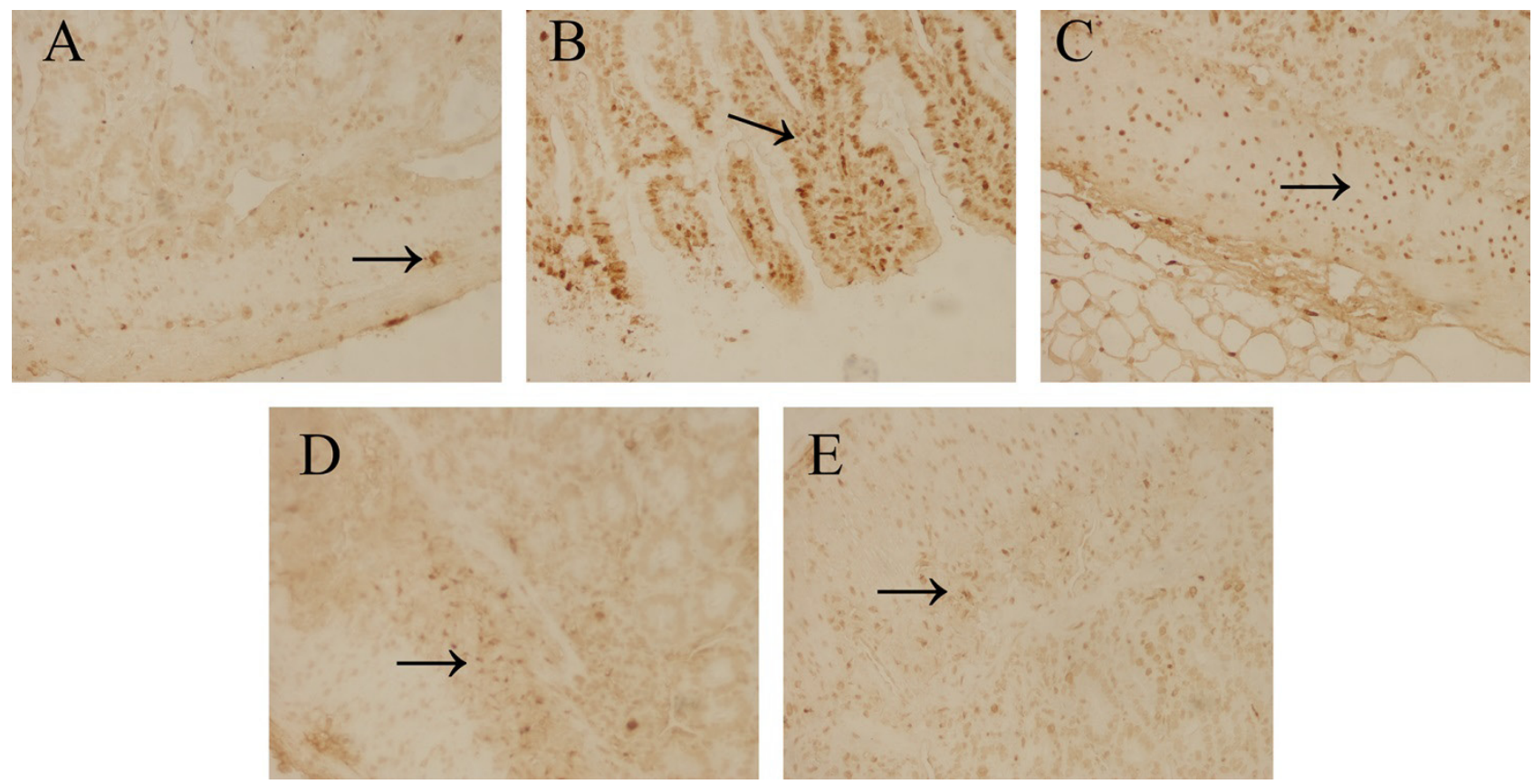

Fig. 4. The pathological sections of intestinal tissue and TUNEL staining in the sham group (6A), in the CLP group (B), in the CTX group (C), in the imipenem+NS group (D) and in the imipenem+NS+CTX group (E). The arrows indicate the apoptosis cells.

$1.5 \mathrm{~d}, 1.5 \mathrm{~d}, 4.5 \mathrm{~d}$ and $7 \mathrm{~d}$, respectively. The results demonstrate that the combined treatment of imipenem, normal saline and cyclophosphamide can effectively prolong the survival time and number of septic rats.

\section{Measurement of the plasma levels of cytokines TNF- $\alpha$, IL-6 and IL-10}

Compared to the level of plasma TNF- $\alpha$ of the sham group, the level of TNF- $\alpha$ was significantly higher in the CLP group $(P<0.05)$ and reduced to a comparable level in the imipenem+NS+CTX group as that in the sham group $(P<0.05)$ (Fig. 2A). The imipenem+NS group had a higher TNF- $\alpha$ level than the imipenem + NS + CTX group $(P<0.05)$.

Similarly, the level of plasma IL-6 in the sham group was significantly lower than that in the CLP group $(P<0.05)$, the CTX group $(P<0.05)$, imipenem $+\mathrm{NS}$ group $(P<0.05)$ and the imipenem+NS+CTX group $(P<0.05)$ (Fig. 2B). The level of plasma IL-6 was significantly lower in the imipenem+NS+CTX group $(P<0.05)$ than that in 


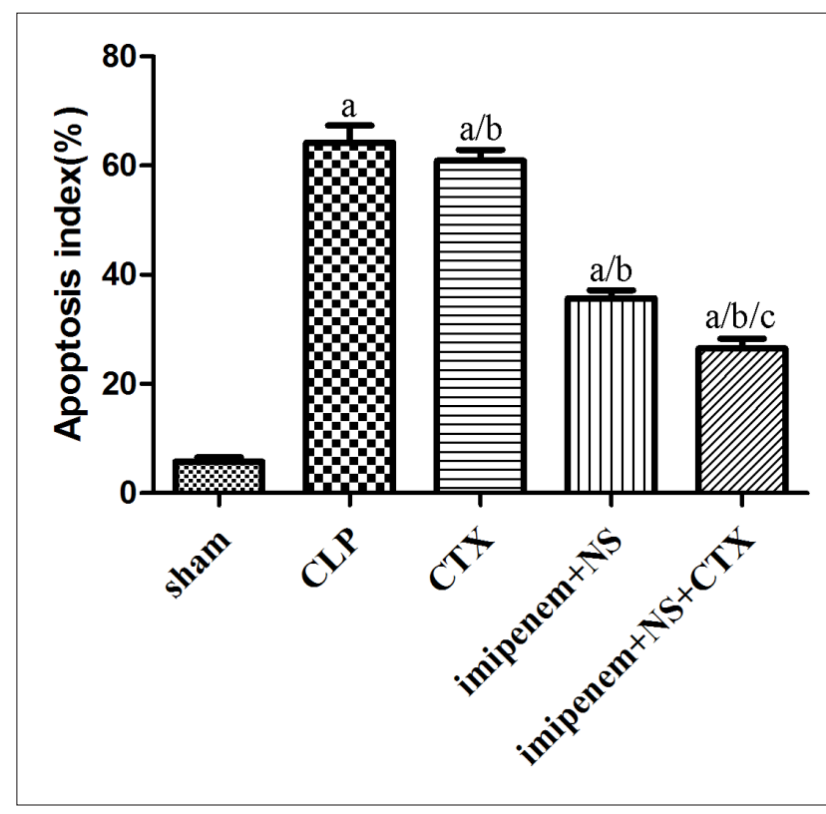

Fig. 5. The quantitative analysis of the apoptosis levels of intestinal mucosal cells.

The values are expressed as mean \pm SD. The statistically significant difference is expressed at $\mathrm{p}$-value of less than $0.05(P<0.05)$. Compared to the sham group, there was statistically significant difference $(P<0.05)$; Compared to the CLP group, there was statistically significant difference $(P<0.05)$.

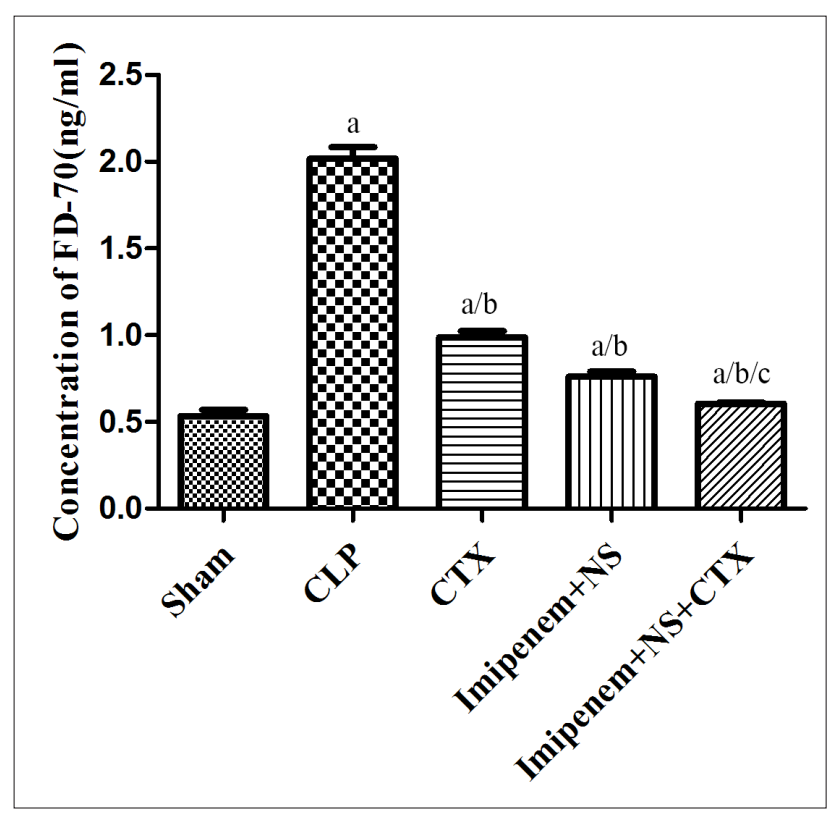

Fig. 6. The levels of serum FD-70 and expressed as mean \pm $\mathrm{SD}(P<0.05)$.

Compared to the sham group, there was statistically significant difference $(P<0.05)$; Compared to the CLP group, there was statistically significant difference $(P<0.05)$; Compared the imipenem+NS group with the imipenem $+\mathrm{NS}+\mathrm{CTX}$ group, there was statistically significant difference $(P<0.05)$.

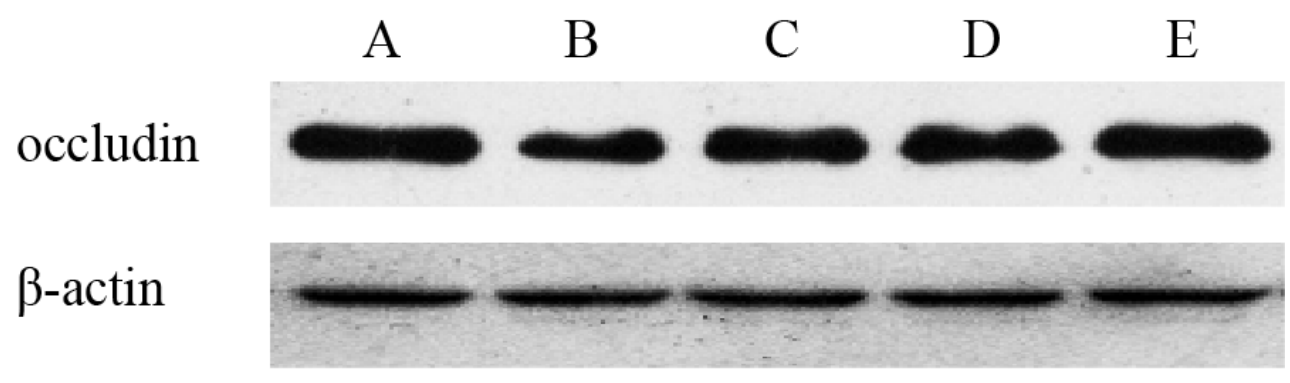

Fig. 7. Western-blot analysis of the occludin protein.

Lane A: sham group; Lane B: CLP group; Lane C: CTX group; Lane D: imipenem+NS group and Lane E: imipenem+NS+CTX group.

the CLP group and the imipenem+NS group $(P<0.05)$. However, there was no significantly significant difference between the CTX group $(P<0.05)$ and the CLP group. Comparing the imipenem+NS group with the imipenem+NS+CTX group, the IL-6 level was statistically significant higher $(P<0.05)$.

For the level of plasma IL-10, there was a significantly higher level in the CLP group $(P<0.05)$, in the CTX group $(P<0.05)$ and in the imipenem $+\mathrm{NS}$ group $(P<0.05)$ compared to the level of IL-10 in the sham group $(P<0.05)$ (Fig. 2C). However, the level of plasma IL-10 was significantly lower in the imipenem+NS+CTX group than other treatment groups $(P<0.05)$. Unlike other factors, the CLP group had statistically significantly lower IL10 level than that in the CTX group $(P<0.05)$ and the imipenem+NS group $(P<0.05)$. Especially, compared to the CLP group, the level of plasma IL-10 was significantly lower in the imipenem+NS+CTX group. Compared to the imipenem+NS group with the imipenem+NS+CTX group, the later had significantly lower level of plasma IL-10 $(P<0.05)$.

Effect of the combination treatment of imipenem and normal saline with cyclophosphamide on the intestinal mucosa in septic rats

Under the light microscope $(\times 100)$, the intestinal mucosal villi were orderly arranged in the sham group, the structure of surrounding blood vessels was normal. There was no obvious bleeding, the muscle fibers were orderly arranged, and the serosa was normal. In the CLP group, the intestinal mucosal villi were severely damaged; mucosal swelling and bleeding were observed around blood vessels, and a fractured basal layer; there were a large number of proliferating lymphocytes; and neutrophils observed (Fig. 3A). 
In the CLP (Fig. 3B) and in the CTX group (Fig. 3C), the intestinal mucosal villi were damaged; mucosal swelling and bleeding around blood vessels; and a fractured basal layer were observed; there were a large number of proliferating lymphocytes; and neutrophils.

In the imipenem+NS group (Fig. 3D), the intestinal mucosal villi were moderately damaged; moderate mucosal swelling and bleeding were observed around blood vessels; and a fractured basal layer was observed; there was a handful of proliferating lymphocytes; and neutrophils were observed (Fig. 3D).

In the imipenem+NS+CTX group, the intestinal mucosal villi were severely damaged; with mild mucosal swelling. Bleeding was observed around blood vessels; and a mildy fractured basal layer; there were a small number of proliferating lymphocytes; and neutrophils but less than that in the imipenem+NS group (Fig. 3E).

\section{Measurement of the apoptosis levels of intestinal mucosal cells}

Under the light microscope $(\times 400)$, we observed the changes of the intestinal mucosal apoptotic cells and calculated the numbers of apoptotic cells and normal cells in one microscopical field of vision, a total of 5 fields was examined, and obtained the apoptosis index (AI) (Table 2 ). The TUNEL assay showed that only a few intestinal mucosal epithelial cells were apoptotic in the sham group (Fig. 4A). However, in the CLP group (Fig. 4B) and in the CTX group (Fig. 4C), a large number of apoptotic cells was observed, happening mainly in the mucosal column such as epithelia and submucosal cells. The apoptotic cells in the CTX group were less than that in the CLP group. In the imipenem+NS group (Fig.4D) and in the imipenem+NS+CTX group (Fig. 4E), a handful of apoptotic cells was observed, happening mainly in the mucosal column such as epithelia.

Compared to the sham group, the apoptosis index of intestinal epithelial cells was significantly higher in the CLP group $(P<0.05)$ (Fig. 5). Compared the CLP group to the CTX group $(P<0.05)$, the imipenem+NS

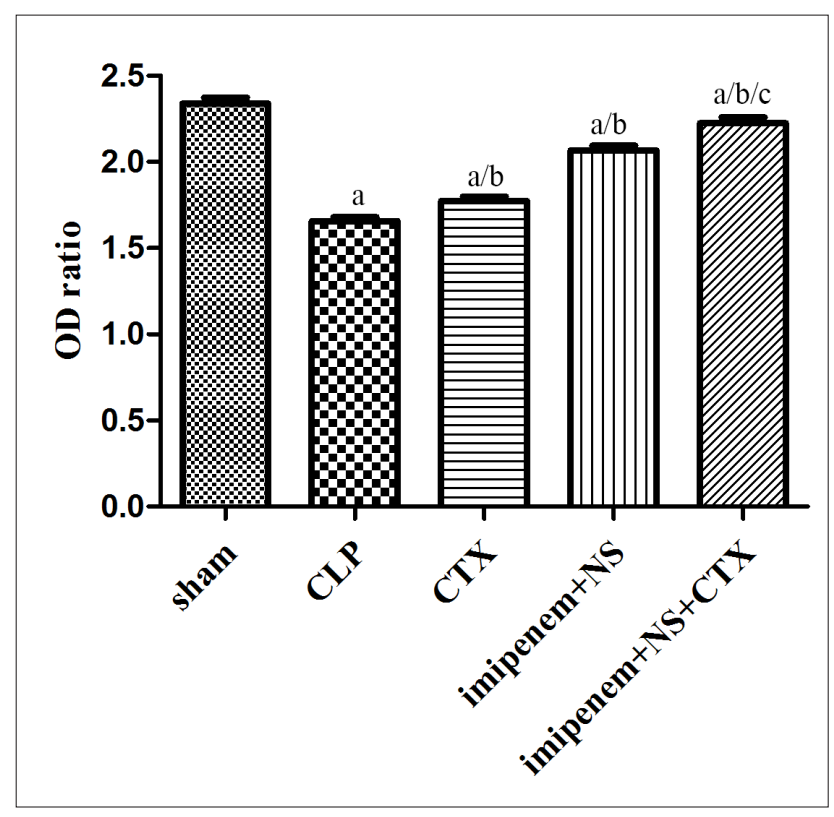

Fig. 8. Quantitative analysis of the occludin protein expression. The levels of the protein expression are expressed as mean \pm SD $(P<0.05)$. Compared to the sham group, there was statistically significant difference $(P<0.05)$; Compared to the CLP group, there was statistically significant difference $(P<0.05)$; Compared the imipenem+NS group with the imipenem+NS+CTX group, there was statistically significant difference $(P<0.05)$.

group $(P<0.05)$ and the imipenem $+\mathrm{NS}+\mathrm{CTX}$ group $(P<0.05)$, the CLP group had the highest apoptosis index, next was the CTX group and then the imipenem+NS group. The imipenem+NS+CTX group had the lowest apoptosis index. The results demonstrated that both the imipenem+NS group and imipenem+NS+CTX group distinctly had a lower number of apoptotic intestinal epithelial cells. Compared the imipenem+NS group with the imipenem+NS+CTX group, there was no statistically significant effect of CTX on the number of apoptotic intestinal epithelial cells $(P>0.05)$.

Table 1. Level of serum IL-6, IL-10 and TNF- $\alpha$.

\begin{tabular}{lccc}
\hline Group $(\mathrm{n}=6)$ & $\begin{array}{c}\text { IL-6 } \\
(\mathrm{pg} / \mathrm{mL})\end{array}$ & $\begin{array}{c}\text { IL-10 } \\
(\mathrm{pg} / \mathrm{mL})\end{array}$ & $\begin{array}{c}\text { TNF- } \alpha \\
(\mathrm{pg} / \mathrm{mL})\end{array}$ \\
\hline Sham & $296.13 \pm 6.93$ & $70.91 \pm 2.53$ & $154.64 \pm 1.77$ \\
CLP & $3470.91 \pm 14.16$ & $675.63 \pm 9.12$ & $863.00 \pm 6.27$ \\
CTX & $3444.15 \pm 6.85$ & $1829.92 \pm 3.75$ & $491.91 \pm 2.25$ \\
Imipenem+NS & $3137.28 \pm 14.97$ & $1534.03 \pm 5.12$ & $460.09 \pm 2.59$ \\
Imipenem+NS+CTX & $462.82 \pm 12.93$ & $101.27 \pm 7.24$ & $165.28 \pm 4.94$ \\
\hline
\end{tabular}

Table 2. Level of serum FD-70 and the number of apoptosis cells.

\begin{tabular}{lccc}
\hline Group $(\mathrm{n}=6)$ & $\begin{array}{c}\text { Serum level } \\
\text { of FD-70 }(\mathrm{ng} / \mathrm{mL})\end{array}$ & $\begin{array}{c}\text { Occludin } \\
\text { OD ratio }\end{array}$ & $\begin{array}{c}\text { Apoptosis Index } \\
(\mathrm{AI}, \%)\end{array}$ \\
\hline Sham & $0.534 \pm 0.036$ & $2.339 \pm 0.0305$ & $5.74 \pm 0.723$ \\
CLP & $2.019 \pm 0.065$ & $1.656 \pm 0.0221$ & $64.26 \pm 2.780$ \\
CTX & $0.999 \pm 0.035$ & $1.773 \pm 0.0231$ & $60.90 \pm 1.789$ \\
Imipenem+NS & $0.761 \pm 0.029$ & $2.068 \pm 0.0243$ & $35.68 \pm 1.301$ \\
Imipenem+NS+CTX & $0.605 \pm 0.009$ & $2.226 \pm 0.0300$ & $26.48 \pm 1.638$ \\
\hline
\end{tabular}


Effect of combination treatment of imipenem, normal saline and cyclophosphamide on intestinal permeability following sepsis

We also carried out a quantitative analysis of the function of the intestinal barrier (Fig. 6, Table 2), Compared to the sham group, the level of plasma FD-70 was significantly higher in the CLP group $(P<0.05)$, in the CTX group $(P<0.05)$, in the imipenem+NS group $(P<0.05)$ and in the imipenem $+\mathrm{NS}+\mathrm{CTX}$ group $(P<0.05)$. Again, the CLP group had the highest level of plasma FD-70 compared to the other groups, and the imipenem+NS group had a higher level of plasma FD-70 than the imipenem+NS+CTX group $(P<0.05)$.

\section{Effect of combination treatment of imipenem, normal saline and cyclophosphamide on occludin protein expression following sepsis}

Figure 7 shows the results of the qualitative analysis of the occludin protein expression. Stripes of occludin protein were observed in all samples. In the sham group (Lane A), the chromaticity of the stripe was rougher, darker than the stripe in the CLP group (Lane B), which was lighter than any other stripe. Otherwise, we observed that the color of the strips darkened from the CLP group (Lane B) to the CTX group (Lane C), the imipenem+NS group (Lane D) and the imipene+NS+CTX group (Lane E).

We further quantified the expression of the occludin protein using the OD ratios (occludin $\mathrm{OD} / \beta$-actin OD) of the strips with the ImageJ (ImageJ software, USA) (Fig. 8). Compared to the sham group, the OD ratio was significantly lower in the CLP group $(P<0.05)$, the CTX group $(P<0.05)$, the imipenem+NS group $(P<0.05)$ and the imipenem $+\mathrm{NS}+\mathrm{CTX}$ group $(P<0.05)$. Compared to the CLP group, there were statistically significant differences in the OD ratios from those in the CTX group $(P<0.05)$, the imipenem+NS group $(P<0.05)$ and the imipenem+NS+CTX group $(P<0.05)$. Compared the imipenem+NS group with the imipenem+NS+CTX group, there was a significantly higher occluding protein expression in the latter group $(P<0.05)$. The results demonstrated that there are the same trends in both protein intensities and OD ratios and that the combined treatment with cyclophosphamide can effectively refine the intestinal barrier of the SD rat model of sepsis.

\section{DISCUSSION}

The method of treating sepsis with the sepsis bundle and cyclophosphamide is not new. But previously promising targets and therapies shown to be beneficial in animal models of sepsis failed to translate into clinical advanc$\mathrm{es}^{20}$. We report in this study the advantages of a rat model of sepsis using cecal ligation and puncture (CLP) with the combined treatment of imipenem and normal saline with cyclophosphamide for improving the function of the intestinal mucosal barrier.

\section{The function of intestinal mucosal barrier}

The gut is one of the largest immune organs in body system. The intestinal barrier can absorb all kinds of nutrients and preclude bacteria and its metabolites from permeating the blood. Intestinal immune tissue includes immune cells (lymphocyte B,T) and immune molecule (Sig A) and so on ${ }^{21}$. Symptoms of gut failure are nonspecific and therefore not assessable. The composition of the intestinal microbiome, however, is affected by sepsis and this may contribute to the development of organ failure $^{22}$. The intestinal mucosal barrier as the first barrier can prevent intestinal toxic substances from entering into other tissues, organs and the blood circulation. When the intestinal barrier is damaged, bacteria and toxins can enter through the intestinal wall into intestinal lymph nodes, blood, liver, spleen, intestinal flora and other organs ${ }^{23}$. In the intestinal mucosal epithelial cells, the barrier of the mucosal epithelial cells is one of the important structure for maintaining intestinal mechanical barrier between cells $^{24}$. Occludin proteins are a tight junction protein, one of the two forms in the body, and mainly locate in the close connection between the cells after the phosphorylation. Two cells in the outer ring are connected by pulling chains and closed in a fine combination near the cell gap by the protein ${ }^{25,26}$. When occludin distribution and expression tied to small intestinal structure and function are unusual, intercellular spaces are increased, resulting in increased permeability between endothelial cells ${ }^{27}$.

In this study, we observed that the function of intestinal barrier was damaged after CLP, and the expression level of occludin protein in the CLP group was lower than that in other groups. Compared to the CLP group, there were statistically significant differences in occludin expression in the CTX group $(P<0.05)$, in the imipenem+NS group $(P<0.05)$ and in the imipenem+NS+CTX group $(P<0.05)$. Comparing the imipenem $+\mathrm{NS}$ group with the imipenem+NS+CTX group, there was also a statistically significant difference in the occluding expression $(P<0.05)$. The permeability of intestinal mucosal was damaged too. Compared to the CLP group, there were statistically significant differences in permeability in the CTX group $(P<0.05)$, the imipenem+NS group $(P<0.05)$ and the imipenem+NS+CTX group $(P<0.05)$. Comparing the imipenem+NS group with the imipenem+NS+CTX group, there was a statistically significant difference $(P<0.05)$. In the imipenem+NS+CTX group, the function of intestinal mucosa was intact, the expression level of occludin protein was similar to the sham group, and the permeability of the intestinal mucosa was lower than for the CLP group. The combined treatment of imipenem, normal saline and cyclophosphamide provided the best benefit of all treatments.

Cytokines are released in the early period of sepsis, and proinflammatory and anti-inflammatory effects of imbalance will launch the inflammatory cascade reaction including cytokine release. TNF- $\alpha$ is generated by monocyte, macrophages and T-cells and may induce the release of IL-1, IL-6, IL-8 and secondary inflammatory factors. IL- 6 is generated by the cells and tissues (included intestinal tissue) and induced by TNF- $\alpha$ (ref. ${ }^{28}$ ). 
IL-10 forbids the action of immune response ${ }^{29}$, in normal condition, proinflamatory and anti-inflammatory factors keep the cytokine balance ${ }^{30}$. In our results, in the imipenem+NS+CTX group, the level of plasma IL-6, IL10 and $\mathrm{TNF}-\alpha$ were lower than other treatment groups, suggesting that the body may be in a state of recovery through the therapy combined with cyclophosphamide into $24 \mathrm{~h}$. Compared to the CLP group, the levels of plasma IL-6, IL-10 and TNF- $\alpha$ in the imipenem+NS group and the imipenem+NS+CTX group were statistically significantly different in cytokine levels $(P<0.05)$. Comparing the imipenem+NS group with the imipenem + NS + CTX group, the level of plasma IL-6, IL-10 and TNF- $\alpha$ was statistically significantly different in cytokine level $(P<0.05)$. But compared to the CLP group, the level of plasma IL-6 was not statistically significantly different from that of the CTX group, nevertheless, the levels of plasma IL-10, TNF- $\alpha$ were significantly different $(P<0.05)$. We conclude that the therapy supplemented with cyclophosphamide had greatest positive effect. The median individual survival time of the combination treatment of sepsis bundle with cyclophosphamide was obviously higher. However, we cannot explain this because of the lack of clinically experimental evidence.

\section{CONCLUSION}

Our results show that the combination therapy of imipenem, normal saline and cyclophosphamide improves the intestinal barrier function and prolongs the survival time in the SD rat model of sepsis. These provide the foundation for future studies to confirm such beneficial effect in animal and clinical trials.

Acknowledgement: We would like to thank colleagues who carried out the original studies. This research received no specific grant from any funding agency in the public or nor-for-profit sectors.

Ethics: The study protocol was approved by the ethics committee of Shihezi University.

Author contributions: JY, SZ, WZ: Study conception and design; JY, SZ, JW, JZ, JD, PD, ST: Trials process; JY, SZ: Data analysis; JY, SZ, WZ, FW: Manuscript drafts.

Conflict of interest statement: The authors declare that there are no conflicts of interest.

\section{REFERENCES}

1. Rhodes A, Evans LE, Alhazzani W, Levy MM, Antonelli M, Ferrer R, Kumar A, Sevransky JE, Sprung CL, Nunnally ME, Rochwerg B, Rubenfeld GD, Angus DC, Annane D, Beale RJ, Bellinghan GJ, Bernard GR, Chiche JD, Coopersmith C, De Backer DP, French CJ, Fujishima S, Gerlach H, Hidalgo JL, Hollenberg SM, Jones AE, Karnad DR, Kleinpell RM, Koh Y, Lisboa TC, Machado FR, Marini JJ, Marshall JC, Mazuski JE, Mclntyre LA, McLean AS, Mehta S, Moreno RP, Myburgh J, Navalesi P, Nishida O, Osborn TM, Perner A, Plunkett CM, Ranieri M, Schorr CA, Seckel MA, Seymour CW, Shieh L, Shukri KA, Simpson SQ, Singer $\mathrm{M}$, Thompson BT, Townsend SR, Van der Poll T, Vincent JL, Wiersinga WJ, Zimmerman JL, Dellinger RP. Surviving Sepsis Campaign: International Guidelines for Management of Sepsis and Septic
Shock: 2016. Intensive Care Med 2017;43(3):304-77. doi: 10.1007/ s00134-017-4683-6

2. Singer M, Deutschman CS, Seymour CW, Shankar-Hari M, Annane D, Bauer M, Bellomo R, Bernard GR, Chiche JD, Coopersmith CM, Hotchkiss RS, Levy MM, Marshall JC, Martin GS, Opal SM, Rubenfeld GD, van der Poll T, Vincent $J$, Angus DC. The Third International Consensus Definitions for Sepsis and Septic Shock (Sepsis-3). JAMA 2016;315(8):801-10. doi: 10.1001/jama.2016.0287

3. Angus DC, Linde-Zwirble WT, Lidicker J, Clermont G, Carcillo J, Pinsky MR. Epidemiology of severe sepsis in the United States: analysis of incidence, outcome, and associated costs of care. Crit Care Med 2001;29(7):1303-10.

4. Vincent JL. Cardiovascular management of septic shock. Infectious Disease Clinics of North America 1991;5(4):807.

5. Mayr FB, Yende S, Angus DC. Epidemiology of severe sepsis. Virulence 2014;5(1):4.

6. Dellinger RP, Carlet JM, Masur H, Gerlach H, Calandra T, Cohen J, GeaBanacloche J, Keh D, Marshall JC, Parker MM, Ramsay G, Zimmerman $J$, Vincent JL, Levy MM. Surviving Sepsis Campaign guidelines for management of severe sepsis and septic shock. Intensive Care Med 2004;30(4):536-55.

7. Schmidt EJ, Boswell JS, Walsh JP, Schellenberg MM, Winter TW, Li C, Allman GW, Savage PB. Activities of cholic acid-derived antimicrobial agents against multidrug-resistant bacteria. J Antimicrob Chemother 2001;47(5):671-4.

8. Wilson KH. The Microecology of Clostridium difficile. Clin Infect Dis 1993; 16 Suppl 4:S214-8.

9. Chen J, Xuan J, Gu YT, Shi KS, Xie JJ, Chen JX, Zheng ZM, Chen Y, Chen $X B$, Wu YS, Zhang XL, Wang XY. Celastrol reduces IL-1 $\beta$ induced matrix catabolism, oxidative stress and inflammation in human nucleus pulposus cells and attenuates rat intervertebral disc degeneration in vivo. Biomed Pharmacother 2017;91:208-19 doi: 10.1016/j.biopha.2017.04.093

10. Brown I, Bellevue O, Shawo A, Woldesemayat H, Lyo V, Rayikanti B, Lee M, Uzosike ED, Kasravi S, Harris HW. Low-dose cyclophosphamide improves survival in a murine treatment model of sepsis. Shock 2015 Jan;43(1):92-8. doi: 10.1097/SHK.0000000000000263

11. Dejager $L$, Pinheiro I, Dejonckheere E, Libert C. Cecal ligation and puncture: the gold standard model for polymicrobial sepsis? Trends Microbiol 2011;19(4):198.

12. Rittirsch D, Huber-Lang MS, Flierl MA, Ward PA. Immunodesign of experimental sepsis by cecal ligation and puncture. Nature Protocols 2009;4(1):31.

13. Dellinger RP, Levy MM, Rhodes A, Annane D, Gerlach H, Opal SM, Sevransky JE, Sprung CL, Douglas IS, Jaeschke R, Osborn TM, Nunnally ME, Townsend SR, Reinhart K, Kleinpell RM, Angus DC, Deutschman CS, Machado FR, Rubenfeld GD, Webb S, Beale RJ, Vincent JL, Moreno R; Surviving Sepsis Campaign Guidelines Committee including The Pediatric Subgroup. Surviving Sepsis Campaign: international guidelines for management of severe sepsis and septic shock, 2012. Intensive Care Med 2013;39(2):165-228. doi: 10.1007/s00134-012-2769-8

14. Spoelstra-de Man AM, Girbes AR. Comment on "Surviving Sepsis Campaign: International guidelines for management of severe sepsis and septic shock: 2008" by Dellinger et al. Intensive Care Med 2008;34(6):1160-2; author reply 1163-1164.

15. Bian J, Zhou Z, Zhang X. Influence of ceftriaxone and imipenem to sepsis in the rat intestinal flora and bacterial drug resistance. Chinese Journal of Biochemical and Pharmaceuticals. 2014;34(3):11.

16. Brown I, Bellevue O, Shawo A, Woldesemayat H, Lyo V, Rayikanti B, Lee M, Uzosike ED, Kasravi S, Harris HW. Low-dose cyclophosphamide improves survival in a murine treatment model of sepsis. Shock 2015;43(1):92-8. doi: 10.1097/SHK.0000000000000263

17. Choudhury S, Kannan K, Pule Addison M, Darzi SA, Singh V, Singh TU, Thangamalai R, Dash JR, Parida S, Debroy B, Paul A, Mishra SK. Combined treatment with atorvastatin and imipenem improves survival and vascular functions in mouse model of sepsis. Vascul Pharmacol 2015;71:139-50.

18. Yang B, Huang W, Han J, Liang Z. Study of the role of epidermal growth factor on lung fluid transport in rabbits with acute lung injury caused by endotoxin. Exp Ther Med 2012;4(4):611-4.

19. Mittal R, Coopersmith CM. Redefining the gut as the motor of critical illness. Trends in Mol Med 2014;20(4):214-23.

20. Osuchowski MF, Remick DG, Lederer JA, Lang CH, Aasen AO, Aibiki 
M, Azevedo LC, Bahrami S, Boros M, Cooney R, Cuzzocrea S, Jiang Y, Junger WG, Hirasawa H, Hotchkiss RS, Li XA, Radermacher P, Red $H$, Salomao R, Soebandrio A, Thiemermann C, Vincent JL, Ward P, Yao YM, Yu HP, Zingarelli B, Chaudry IH. Abandon the mouse research ship? Not just yet! Shock 2014;41(6):463-75. doi: 10.1097/ SHK.0000000000000153

21. Gao J. The mucosal immunology raises new questions for immunology. Current Immunology 2000;20(5):257-9.

22. Haak BW, Wiersinga WJ. The role of the gut microbiota in sepsis. Lancet Gastroenterol Hepatol 2017;2(2):135-43.

23. LI J. Intestinal failure - concept, nutritional support and maintenance of intestinal mucosa. Parenteral \& enteral nutrition. 2004(02):65-7.

24. Tian J. The research progress of intestinal mucosal barrier. The Journal of Medical Theory and Practice 2013(15):1964-93.

25. Berkes J, Viswanathan VK, Savkovic SD, Hecht G. Intestinal epithelial responses to enteric pathogens: effects on the tight junction barrier, ion transport, and inflammation. Gut 2003;52(3):439.

26. Johansson ME, Phillipson M, Petersson J, Velcich A, Holm L, Hansson
GC. The inner of the two Muc2 mucin-dependent mucus layers in colon is devoid of bacteria. Gut Microbes 2010;105(1):15064-9.

27. Yang F, Wang A, Zeng X, Hou C, Liu H, Qiao S. Lactobacillus reuteri 15007 modulates tight junction protein expression in IPEC-J2 cells with LPS stimulation and in newborn piglets under normal conditions. Bmc Microbiology 2015;15(1):32.

28. Ren $Y$, Zhang Y. Sepsis and inflammation factor. Paper presented at: Academic conference on national trauma recovery poisoning in emergency medicine branch of Chinese medical association 2005.

29. Sanz MG, Loynachan A, Horohov DW. Rhodococcus equi hyperimmune plasma decreases pneumonia severity after a randomised experimental challenge of neonatal foals. Veterinary Record 2016;178(11):vetrec-2015-103095.

30. Zhu W, Wang J, Liu Y, Lou Q, Chen X. Effects of dexmedetomidine hydrochloride on perioperative serum cytokines and high mobility group protein B1 in patients with sepsis. Chinese Journal of Nosocomiology 2017;27(3):650-2. 